\title{
A Review on perovskite/silicon Tandem solar cells
}

\author{
Shivani Chauhan ${ }^{1}$, Rachna Singh ${ }^{2}$ \\ ${ }^{1}$ Department of electronics and communication, Jaypee Institute of Information technology, \\ Noida \\ ${ }^{2}$ Department of electronics and communication, Jaypee Institute of Information technology, \\ Noida
}

Ghaziabad, India

Shivu25007@gmail.com

Abstract - The tandem Solar cell has high power conversion efficiency (PCE), so they are taken as the next step in photovoltaic evolution. The tandem solar cell also overcome the limitations of Single-junction solar cells by reducing thermalization losses and also reduce the fabrication cost. The fabrication of tandem solar cells is highly efficient after the origination of halide perovskite absorber material, this material will shape the future of tandem solar cells. Researchers have already shown that this material can convert light more efficiently than standalone sub cell. Today, researchers around the world are keeping the configuration of a tandem solar cell as their agenda. A Tandem solar cell is a stacking of multiple layers having different bandgaps with specific maximum absorption and width. We reviewed perovskite/silicon tandem solar cells with different sub-module configurations. Move forward, we discuss the tandem module technology, sub cell of a tandem can be wired in several ways two terminals $2 \mathrm{~T}$ monolithic and mechanically stacked, a four-terminal 4T mechanically stacked, and three-terminal 3T monolithic stack devices. This review paper provides a side-by-side comparison of theoretical efficiencies of multijunction solar cells. The highest efficiency has been evaluated at $39.4 \%$ for a three-level structure.

Keywords: power conversion efficiency (PCE), perovskite/silicon, 2T, 3T, 4T.

\section{INTRODUCTION}

Solar Photovoltaic technology is one of the most efficient and sustainable technologies, which convert solar energy into reliable and affordable electricity in a one-step conversion process. So, a Photovoltaic (abbreviated as PV) cell is a device that transforms incident solar energy into electrical energy $[1,15]$. With an efficiency of $16 \%$, the first silicon solar cell was reported in 1954 [16] after that in the 1980's efficiency of the solar cells began to increase. Silicon solar cell achieved a milestone of 20\% efficiency in 1985 [2]. Efficiency is defined as the ratio of output energy taken out from solar cells to the incident light coming from the sun. Performance of solar cell can also be compared by this parameter. The efficiency depends on different parameters, such as its fabrication process, band gaps of semiconductor material used, temperature, a doping 
concentration of semiconductor material, etc. These parameters greatly affect the efficiency of a photovoltaic cell. In solar panels, not all the sun's energy is converted into useful energy, some amount of energy is lost by thermalization loss, absorption loss. So, the amount of energy convert into useful energy (electricity) by a certain panel is known as the efficiency of solar panels. A current is generated when sun rays interact with a solar cell in the panel and that would be transferred through the wire and busbars, which they converted into AC (alternating current) energy and then this $\mathrm{AC}$ is distributed throughout the houses. India's Photovoltaic technological capabilities are based on single crystalline silicon solar cell technology [3].

For a single junction Silicon Solar cell, the utmost efficiency we can achieve is $32 \%$ and this limit comes from the thermodynamics limit called the Schockley-Queisser limit. Practically due to some effects like internal resistance, reflection from the face of the cell, recombination of charge carriers, and others reduce the cell efficiency [4]. If we made a solar cell having very high efficiency or very high absorbing material, so that the charge transport \& also charge recombination is optimized to get maximum efficiency, but due to some limitations we cannot go beyond a particular number. Like we need more output power for some applications, the singlejunction solar cell gives $15-20 \%$ efficiency which is not sufficient. The maximum energy that can be extracted per photon and depend on the band parameters for the semiconductor absorber layer, which determines Voc (open-circuit voltage) and $\mathrm{V}_{\mathrm{M}}$. Parameters that limit the efficiency of the cell: (1) Fraction of solar photon absorbed in the cell (2) Electrical energy created per photon. The maximum power of the device is the product of the absorption rate of photons and the mean electrical energy created by the photons [14]. Scientists tried a new way to get more output power. They arranged solar cells in this way (stacked many solar cells) so they capture more energy from the sun. Either of the same kind of solar cell or different kind of solar cell like perovskite-perovskite together or perovskite/crystalline silicon together. This presentation of solar cell known as Tandem solar cell.

Different semiconductor materials will have different efficiencies because of different values for bandgap. In tandem solar cells, semiconductors with different bandgaps are used, they are more efficient than the individual cell on their own. This is because the Tandem cell uses the solar spectrum more efficiently rather than conventional silicon solar cell primarily convert IR(Infrared) component of light efficiently into electrical energy, whereas certain perovskite compound can effectively utilize the visible component of sunlight making this powerful combination [5]. There are other newer solar cell technologies that promise lower-cost solar power, these are the thin-film vapor-deposited semiconductor-based solar cells. Some solutionprocessed solar cells based on hybrid composites, organic and inorganic semiconductors [6,7] such as CIGS or CdTe, are referred to as second or third-generation photovoltaics (PVs).

A Tandem solar cell is made up of various materials such as silicon (monocrystalline, polycrystalline, amorphous) [19], perovskite, polymer, dye-sensitized solar cell [20], and quantum dot solar cell. Tandem solar cells can be operated as two, three, or four-terminal devices. The electrical connections of the tandem solar cell are in series or parallel circuits [17]. Tandem device architecture consists of narrow-bandgap $(\sim 1.2 \mathrm{eV})$ and wide-bandgap $(\sim 1.7-1.9$ $\mathrm{eV}$ ) layers that have the potential to exceed the SQ (Shockley- Queisser) limit of the single- 
junction device and also capable of reducing losses i.e thermalization loss and proper utilization of solar spectrum $[8,11]$. This is often particularly essential to form efficient tandem solar cells, which offer the possibility of surpassing the fundamental Shockley-Queisser limit on the potency of a single junction solar cell. Perovskite is maybe an artificial material and most promising rising thin-film PV technologies and additionally referred to as 3rd generation PVs. Perovskite contains properties like wide absorption spectrum, long transport distance of holes and electrons, fast charge separation, high charge mobility, long carrier separation lifetime, and more, hold promises for high efficiencies and also reduce processing cost [18].

Few Reviews have been Published that summarize the event of the perovskite Solar cell. Improvement of PCE (Power Conversion Efficiency) has been the main driver of research so far. Herein, we present a review on the potency of different configurations of tandem solar cells and factors that affect the potency of various configurations. Based on perovskite multijunction solar cells we discuss here module configurations $2 \mathrm{~T}, 3 \mathrm{~T}$, and $4 \mathrm{~T}$. The three-terminal (3T) tandem solar cell can overcome the limitations of two-terminal (2T) and four-terminal (4T) solar cell designs. A brief description of the three-terminal tandem solar cell is discussed in section IV and also shown that three-terminal devices can work on efficiency above $30 \%$ if properly designed. We compare the efficiency of different module configurations of a perovskite/silicon tandem solar cell because efficiency is a parameter that aggregates many parameters like fundamental properties of the material, fill factor, open-circuit voltage, short-circuit current, and manufacturing defects.

\section{TANDEM SOLAR CELLS}

There are Energy losses during the conversion of solar energy into electrical energy are thermalization losses and transmission losses. To overcome or reduce these losses several strategies exist such as hot-carrier solar cell, intermediate band solar cell, multijunction, or tandem solar cell. These multijunction cells are the only concept which surpasses the SQ limit and reached industrial applications. Thermalization loss occurs when an electron is excited by a photon with energy higher than the band-gap energy. Transmission loss occurs when photons are not absorbed due to lower bandgap as shown in figure 1(a) but when we stack two or more layers this loss can be reduced. For this the band-gap of first layer should be wide, so that photons having low-energy can pass the first layer and second layer should have lower band-gap. This is how tandem configuration reduces thermalization and transmission losses [21]. 


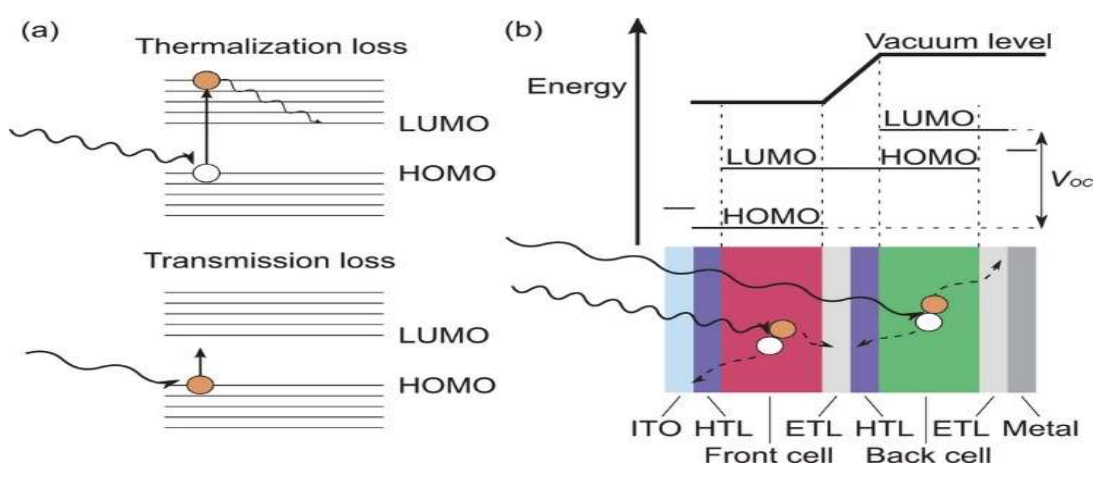

Figure 1: (a) Thermalization and transmission losses. (b) showing energy and functional layers of organic tandem solar cell. Interconnecting layer form by stack ETL/HTL between sub-cells [22].

Understanding of tandem solar cell is very simple, as tandem solar cell consist of stacked layered structure, these layers have tunable bandgaps and arrangement of these layers in such a way to reduce the losses corresponding to single-junction cells. Also, increasing the number of junctions may leads to decrease the absorption loss and also increase the overall spectral sensitivity of the device. Thickness of these layers can also have great impact on the performance of tandem solar cell, also each sub-cell should have to be current matched [23]. The stacking process of tandem junctions can be done mechanically. There is a limitation of monolithically grown tandem devices, as mismatching of lattice parameter and thermal expansion coefficients of the material used [24]. As shown in figure 1(b), layers of tandem can be stacked electrically and optically. The Interconnecting layer (ICL) is an optically transparent which support the photocurrent by passing the light and for the recombination of electron and holes make electric contact with the adjacent photoactive layers. In the adjacent photoactive layers, the fermi level of the HTL (Holetransporting layer) and the ETL (Electron-transporting layer) jointly form the ICL must match the levels of highest occupied molecular orbital (HOMO) and lowest unoccupied molecular orbital (LUMO). Voltage losses and low resistance should not cause by the ICL layer. The sum of open circuit current of sub cell is equal to the open circuit current of tandem solar cell and the induced photocurrent is short by generation of less current by the sub-cells [22].

The metamorphosis of photon to electron, the external quantum efficiency is defined as the incident photons of a particular wavelength to the number of electrons produced by an external circuit. Expression for EQE is given by equation (1) [25].

$\mathrm{EQE}(\lambda)=\eta \mathrm{A}(\lambda) \times \eta \operatorname{ED}(\lambda) \times \eta \mathrm{CD}(\lambda) \times \eta \mathrm{CC}(\lambda)$

The PCE (power conversion efficiency), $\eta(\%)$, of a photovoltaic device is given by the equation

$\eta=(\mathrm{J} \mathrm{sc} \times \operatorname{Voc} \times \mathrm{FF}) /(\mathrm{Pin})$

where Jsc is the short-circuit current density, Voc is the open-circuit voltage, FF is the fill factor, and Pin is the power of incident light. $\mathrm{V}_{\mathrm{OC}}$ is the maximum potential at which there is no current, Jsc is influenced by the breadth of the light absorption spectrum, the extent of light absorption, and the morphology of the active layer. A thickness of the active layer is defined how much light is absorbed. What is best in tandem technology is we can integrate top and bottom cells in 
multiple ways. This various module configuration assumes different material systems, fabrication methods, bandgaps, cell structures and many others. Classification of tandem solar cells can be depending on the interconnection schemes or on the fabrication. Herein figure 2, we classify the tandem solar cell as type A and type B based on number of transparent conductive electrodes (TCEs) [26,27]. In figure 2 (a) two-terminal monolithic tandem is shown which grown on a single substrate. As this configuration requires a smaller number of processing steps, interconnections and layers, this can be used as commercial products.

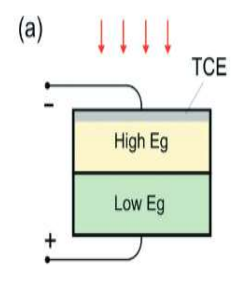

2-T

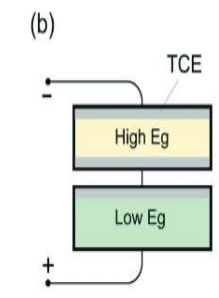

2-T

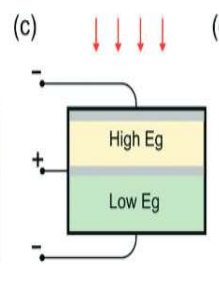

3-T

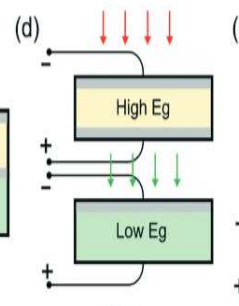

4-T

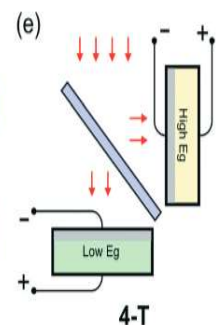

4-T

TYPEA(SINGLE TCE)

TYPE B (MULTI TCE)

Figure 2: Configuration of tandem solar cell based on number of TCEs and terminal connections: (a) type A: Two-terminal monolithic with single TCE (b) Two-terminal mechanically stacked with two TCE and falls in Type B (c) Three-terminal monolithically stack (d) four-terminal mechanically stack (e) and the last one which falls in type B is four-terminal spectrum-split [27].

In Series connected two-terminal (2T) configuration, the generated carriers transport from one sub-cell to another sub-cell through the conductive layer. As the sub-cells are connected in series, they need to match the current and the material having suitable bandgap is used, which limits the choice of material. 2T connection imposes an important boundary condition - that the current in both sub-cells must remain equal [28]. This condition requires precise current matching to achieve optimal output power. The two-terminal (2T) device is difficult to fabricate, problems face to fabricate $2 \mathrm{~T}$ are (1) Current should be matched for both sub-cells. (2) fabrication of recombination layers with a minimal loss between the cells. (3) optical management within the tandem. Research and development of monolithic two-terminal device (Type A solar cell is shown in figure 5(a)) are challenging because it requires precise optical and current matching between individual devices and requires compatibility processing step with all preceding layers and interfaces. Device isolation for type A configuration is also challenging because it requires an auxiliary element like TCO, without this element stacking is almost impossible. Over monolithically stacked 2T the mechanically stacked 2T (shown in figure 2(b)) have an advantage by adjusting the area of solar cell so that the current matching requirement can be relaxed, also the interfacial tunneling is removed. Hence these mechanically stacked $2 \mathrm{~T}$ require more TCE layers and also reduces optical losses.

Next in figure 2 (d) is mechanically stacked four-terminal tandem, in this the sub cell are vertically stacked but an advantage of this $4 \mathrm{~T}$ is all the terminals of sub cell are operated individually to get the maximum power. This four-terminal device works like two diodes means the incident light is split into two diodes and these diodes works electrically independent. 4T also 
have a wide variety of bandgaps, so the energy conversion efficiency can exceed upto $40 \%$. The total power conversion efficiency for $4 \mathrm{~T}$ can be calculated by the power generated by these diodes independently and then sum up. Another configuration in figure 2(e) is four-terminal spectrum split. It has its own advantage of flexibility, it also operates as stand-alone solar cell, reduces the optical losses as it requires only two TCEs instead of three TCEs as in mechanically stacked 4T.

The last configuration left in figure 2(c) is three-terminal monolithically stacked tandem, it is similar to $2 \mathrm{~T}$ device only the difference is it requires an interdigitated back contact (IBC) bottom cell having two contact of opposite polarity on the back [29]. It is understood that 2T tandem cell with a single front-back (FB) circuit, where two cells are connected with a transparent conducting adhesive (TCA) or with tunnel junction (TJ), and an additional second terminal is created at the bottom cell, but these two are not independent [29,30]. In the 3T configuration, the two circuits share a terminal, therefore they are not independent and cannot be measured separately, with their outputs added.

The short-circuit current is the factor by which power conversion efficiency of the tandem solar cell is determined. So, the maximum power conversion efficiency is depending on the shortcircuit current of top and bottom diode bandgap combinations. The short-circuit current of tandem solar cell is said to be matched if the short-circuit current of both top and bottom diode is equal. Assuming the tandem cell has been optimized for AM1.5, this will pass through the topcell and generate the most current in the bottom-cell, An Air Mass 1.5 spectrum is used as a standardized optical input spectrum [53]. The theoretical efficiency limit for a tandem solar cell under unconcentrated sunlight (AM1.5 spectrum) is 47\% markedly higher than the SchockleyQuiesser limit of $31 \%$ for a single-junction cell under unconcentrated sunlight.

\section{PEROVSKITE BASED MULTIJUNCTION SOLAR CELL}

A Russian mineralogist whose name is L.A. Perovski, and perovskite is the mineral $\left(\mathrm{CaTiO}_{3}\right)$ named after him. The structure of perovskite consists a compound $\mathrm{ABX}_{3}$, where $\mathrm{A}$ is some organic/inorganic cation, $\mathrm{B}$ is some heavy metal and $\mathrm{X}$ denotes halogen family such as $\mathrm{Cl}, \mathrm{Br}$ $[9,12]$. The highest reported efficiency perovskite material is lead methylammonium lead triiodide (CH3NH3PbI3, MALI), with a bandgap of $\sim 1.50-1.57 \mathrm{eV}$. The bandgap (Eg) of the perovskite material can be continuously tuned by simple compositional substitution from around 1.6 to $2.3 \mathrm{eV}[10,13]$. Material having a smaller bandgap is necessary for yielding the wider range of the solar spectrum [28]. A thin layer of $2 \mathrm{~mm}$ of perovskite absorbed most of the incoming light, suitable for the high-efficiency solid-state sensitized solar cells. The charge accumulation is linearly depending on current. One of the properties of perovskite is charge accumulation and we identified this by the impedance measurement. The wavelength is expected to be around $826 \mathrm{~nm}$ for absorption based on the band-gap energy.

Transparent contacts and recombination layers for perovskite Tandems: Two critical requirements for transparent contact and recombination layers in a tandem device, (1) high transmittance (2) minimal electrical losses. The two are interrelated and the choice of material depends on tandem configuration layer sensitivity to various deposition methods and the choice 
of adjacent charge selective transport layers. The top contact of tandem solar cell must have great transparency. The rear and front contact of top and bottom cell should be transparent for subbandgap light from the near IR onwards in 4T tandem. All contact must minimize voltage losses. The choice of material for each contact is dependent on several factors including bandgap alignment, temperature/impact sensitivity of the underlying cell layer, and location in the tandem stack.

\section{PEROVSKITE/SILICON MULTIJUNCTION SOLAR CELL}

In this topic we discussed the recent progress of monolithic Perovskite/silicon tandem solar cell. up to now we have already discussed about some of the parameters i.e power conversion efficiency, top-cell performance, bandgaps etc. all effect the performance of tandem solar cell. For the single-junction perovskite solar cell the power conversion efficiency (PCE) has been reached to $22.7 \%$ [57]. Already several papers already explain the performance and different tandem configurations (2T, 4T) [64]. As we discuss this earlier that 4T tandem doesn't require any electrical coupling or current matching and for optical coupling only require the top-cell to be made of semi-transparent, hence it is easier to prototype. This explains why 4T was first to choose to record single-junction Si efficiencies (26.4\%) in early 2017 [65]. In section II we also discussed how challenging is to fabricate $2 \mathrm{~T}$ tandem. The first $2 \mathrm{~T}$ perovskite/Si with the efficiency of $13.7 \%$ is disclose in 2015 [66]. This was based on conventional crystallized p++-Si/ $\mathrm{n}++-$ Si tunneling layer, which gives Voc of $1.6 \mathrm{~V}$ and fill factor is 0.75 with the short-circuit current density (Jsc) of $11.5 \mathrm{~mA} \mathrm{~cm}^{-2}$ results with the efficiency of $\approx 13.7 \%$ [66]. The recent best recorded efficiency for $2 \mathrm{~T}$ perovskite/Si tandem is $\approx 28 \%$, this is also better for $4 \mathrm{~T}$ perovskite/Si tandem not only for single-junction Si record [65]. But this technique also has a limitation that they require a post-treatment at high temperature by which they activate the dopants in the tunneling layer. Due to which this technique needs a temperature tolerant silicon sub cell. To handle this problem a tunnel junction of a hydrogenated nanocrystalline silicon is fabricated by the process of plasma -enhanced chemical vapor deposition (PECVD), used silane gas diluted with hydrogen. By the implementation of tunnel junction in such a way that drive the efficiency to $\approx 22 \%$ and this also brings improvement in short-circuit current density to over $16 \mathrm{~mA}^{-2}$ [67].

Figure 3 depicts plots of theoretical double-junction tandem solar cell power conversion efficiencies (PCEs) versus bottom and top cell bandgaps in both monolithic two-terminal (2T) (Fig. 3a) and mechanically stacked four-terminal (4T) configurations (Fig. 3b) along with the bandgap combinations used in current state-of-the-art perovskite-based tandems. Theoritical efficiency limit calculated with thickness of different sub cell, each bandgap combination picked to optimize the performance for 2T tandems. Grey shading signifies anything below the SQ limit of $32 \%$ for a SJ with a $1.1 \mathrm{eV}$ bandgap, indicating where there is no efficiency gain in building a tandem device. The metal halide perovskite semiconductors are accessible by the dotted white line mark the lowest bandgap currently. The theoretical efficiency was calculated as follows. The short-circuit current was calculated by integrating the AM1.5G spectrum assuming 100\% EQE above the bandgap. The reverse saturation current was calculated from detailed balance as by Shockley Queisser in 1961[70] assuming 100\% radiative emission. Assuming the ideal diode equation applies, an I-V curve was simulated from these quantities. To determine a tandem efficiency first taken the short-circuit current in the wide-band gap cell or half the current produced by the low-gap (whichever is smaller) then to combine the I-V curve of two sub cell 
Kirchhoff's rule is applied for a monolithic (series-connected) tandem. For mechanically stacked device, the efficiency was simply taken as the sum of the best possible sub cell efficiencies and also constraints do not apply.

$2 \mathrm{~T}$ tandems consist of two series-connected sub cell of different bandgaps, so that the current through each sub cell must be identical, resulting in a 'current matching' requirement. Because 4T tandems are not necessarily connected in series, they are not limited by current matching, making them less sensitive to the exact bandgap combination chosen. They are easier to prototype, but suffer from parasitic absorption and reflections from additional transparent reflections and interfaces, which should ultimately result in lower practical efficiencies. The figure below demonstrates that it is critical to select absorbers with appropriate bandgaps for both sub cell, especially when developing $2 \mathrm{~T}$ tandems, and that bandgap combinations with high efficiency limits are readily accessible for metal halide perovskite absorbers.

(a)

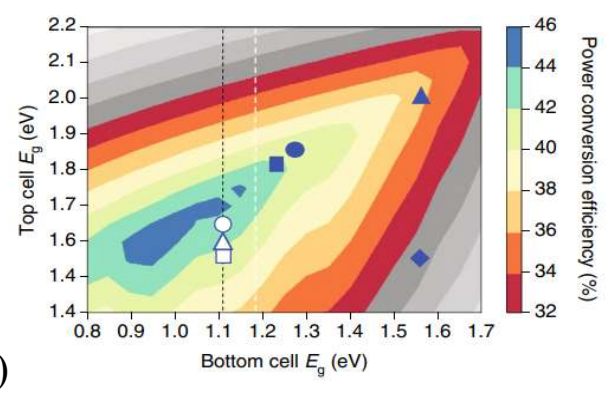

(b)

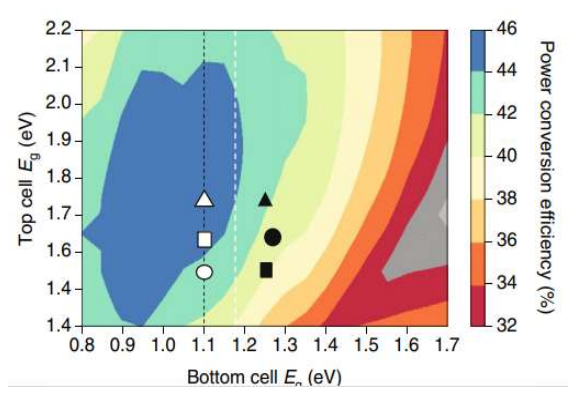

Figure 3: (a) Theoretical efficiency limit for 2T tandems (b) Theoretical efficiency limit for 4T tandems.

The black dotted line in Fig. a,b represents the $\sim 1.1 \mathrm{eV}$ bandgap of c-Si. These could be ideally paired with perovskites in the 1.6-1.75 eV range to yield limiting performances of $\sim 44 \%$. This type of 'hybrid' tandem approach, where perovskites provide a boost in efficiency for little additional cost, presents an exciting path to delivering higher-efficiency panels without significant additional costs or changes to existing c-Si manufacturing lines and supply chains. As a result, the perovskite-Si tandem has been the focus of a great deal of research and has recently reached efficiencies of $23.6 \% 18$ and $26.4 \%$ in $2 \mathrm{~T}$ and $4 \mathrm{~T}$ configurations, respectively, approaching the world record c-Si performance of $26.6 \%$.

\section{A. 2 T Perovskite/silicon Tandem solar cell}

Efficiency of 25 to $26 \%$ is achieved with the use of TCO recombination layer, this has been one of the highest recorded efficiency for $2 \mathrm{~T}$ tandem $[68,69]$ and for the large-area $\left(16 \mathrm{~cm}^{2}\right)$ tandem solar cell the highest recorded efficiency is $21.8 \%$ which can be achieved without using of interlayer [64]. In the $2 \mathrm{~T}$ monolithically integrated device, the top sub cell is directly processed on the bottom sub cell shown in figure 4(a). In 2015 the first working 2T perovskite/Si tandem based on conventional crystallized $\mathrm{p}++-\mathrm{Si} / \mathrm{n}++-\mathrm{Si}$ tunneling layer with the efficiency of $13.7 \%$ is reported, this configuration results with $\mathrm{Voc} \approx 1.6 \mathrm{~V}$ and fill-factor $=0.75$ as shown in figure 5(a). They fabricated a standard mesoporous MAPbI3-based sub cell with silver nanowires (AgNWs), Spiro-OMeTAD and TiO2 acting as front contact, HSL and ESL, respectively, on top of an n-type Si sub cell. To allow the recombination of electrons from perovskite passing through the TiO2 film with holes arising from the Si-based sub cell, they utilized an $n++/ p++$ tunnel 
junction. The process used for the deposition of this layer is plasma-enhanced chemical vapor deposition, in this layer a heavily doped $n++$ hydrogenated amorphous silicon is combined with $\mathrm{p}++\mathrm{Si}$ emitter. The performance of this device has a moderate hysteresis $(13.7 \%)$, which is probably due to the use of non-state-of-the-art perovskite and silicon material.

To fabricate double-junction devices based on the best-performing silicon technology, i.e., the a$\mathrm{Si}: \mathrm{H} / \mathrm{c}-\mathrm{Si}$ silicon heterojunction (SHJ), the device needs to work at temperatures below 200C to prevent undesirable $\mathrm{H}$ mobility at the a-Si:H layer. With this in mind, in [63] reported a lowtemperature approach for the complete fabrication process of the tandem device. They replaced the standard $\mathrm{TiO}_{2} \mathrm{ESL}$, which requires a $500^{\circ} \mathrm{C}$ annealing, by an $\mathrm{SnO}_{2} \mathrm{ESL}$ deposited at room temperature by atomic layer deposition (ALD). In this case, the recombination layer. between sub cell is formed by $\mathrm{SnO} 2$ and ITO film. Moreover, better-quality perovskite composition, FAyMA1-yPbIxBr $3-\mathrm{x}$, and a Spiro-OMeTAD/ $\mathrm{MoO}_{3} / \mathrm{ITO}$ front contact were used to prepare the top cell. The perovskite/Si tandem solar cell pushes the performance to a stabilized PCE 18.1\% by the combination of those improvements. In addition, in [62] showed that low-temperature organic PEIE/ PCBM ESL could be used to substitute the standard TiO2 ESL in order to attain devices with a recombination layer based on indium zinc oxide (IZO) between perovskite and SHJ sub cell [62]. The deposition of $\mathrm{MoOx}$, hydrogenated $\mathrm{In}_{2} \mathrm{O}_{3}$ and transparent front contact of ITO is used to yield high current with negligible hysteresis (19.2\%). As pointed out by the exhaustive work of Filipic and others, $[61,54,50]$ the use of randomly distributed pyramids to texture the c-Si surface reduces the reflection and increases the optical path length in the cell. Indeed, [79] make use of this effect to increase the efficiency of a $1.43 \mathrm{~cm}^{2}$ two-terminal perovskite/silicon tandem device from $19.2 \% 70$ to $20.5 \%$ (Figures 5(d)) [49]. Nevertheless, concerns over the long stability of this tandem configuration arise, since the MoOx HSL may react with the perovskite. More recently, the experimental demonstration of a more stable perovskite, with $\mathrm{Cs}_{0.17} \mathrm{FA}_{0.83} \mathrm{~Pb}\left(\mathrm{Br}_{0.17} \mathrm{I}_{0.83}\right)_{3}$ formulation,[48] has opened the path to a record perovskite/silicon double-junction device, they made a perovskite solar cell in which the thermal and moisture stability of the perovskite compound tolerates the sequential deposition of $\mathrm{SnO} 2$, ZTO, and ITO by ALD, pulsed-chemical vapor deposition, and sputtering, respectively, as electron selective front contact of the solar cell. This transparent contact window ensures negligible parasitic absorption and acts as a diffusion barrier, leading to $23.6 \%$ efficiency.

The sub cell are connected with an interconnecting layer in a monolithic perovskite/Si tandem solar cell. This layer recombines completely opposite holes and electrons from the hole transport layer and electron transport layer from bottom and top sub cell, respectively. Neglected voltageloss should be achieved by an excellent interconnecting layer. some demands are need for the recombination layer (1) to reduce the electrical losses electron and holes are collected from the different transport layer by the work function of the recombination layers (2) without damage to the lower layer, recombination layer need to be manufactured at very low temperature (3) to induce the current loss [72], the absorption of bottom cells doesn't affect by the transmittance of recombination layer, so that recombination layer must have high transmittance. TMO is the excellent material which have demanded above properties (low sheet resistance, high transmittance, high conductivity). Some popular material for recombination layers is ITO, IZO and AZO. A voltage loss would be induced because of low shunt resistance of TMOs. There are many candidates for the recombination layer which deposited at very low temperature having high shunt resistance by the process of plasma-enhanced CVD such as n type and ptype Si, dopes 
silicon, amorphous silicon. At very low manufacturing cost and very low temperature the abovementioned materials are replaced by the doped molecule which are combined with lower and upper transparent layer i.e, m-PEDOT: PSS/ $\mathrm{PH}_{1,000} / \mathrm{ZnO}$ and Spiro-OMeTAD/PEDOT:

PSS/PEI/PCBM: PEI. A strategy by which we could easy manufacturing technology by simply combining the two layers from different cells, hole transport layer and electron transport layer. Thus, the recombination layer must provide very good selectivity for the respective charge carriers as well as the favorable energetic alignment for lossless photovoltage addition and low series resistance [73]. Furthermore, it must also provide high optical transparency for the bottom cell (NIR).

(a)

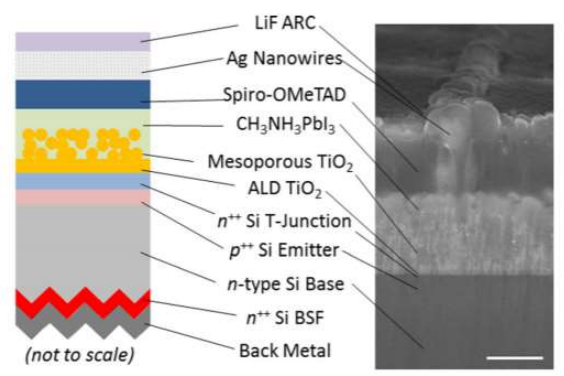

(c)

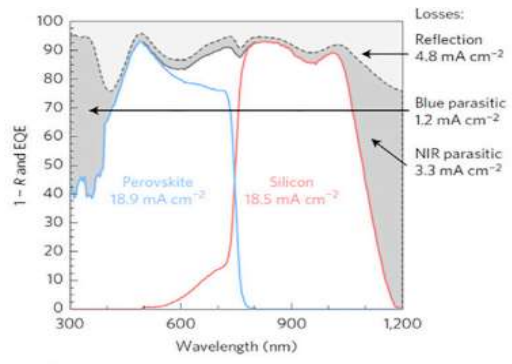

2T tandem

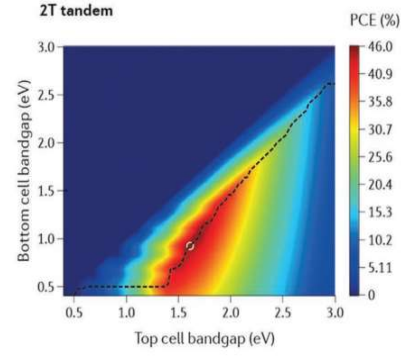

(b)

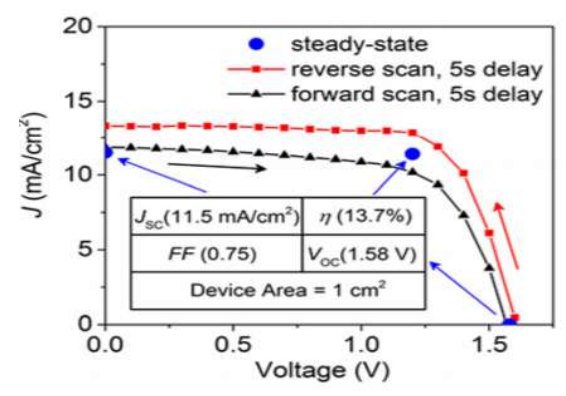

(d)

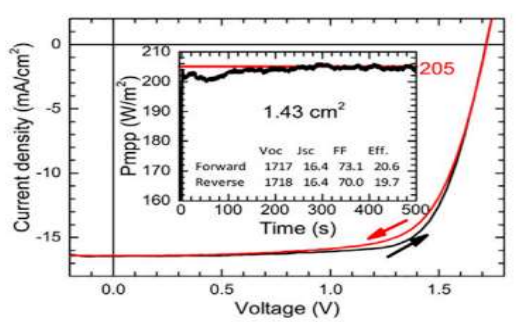

(e)

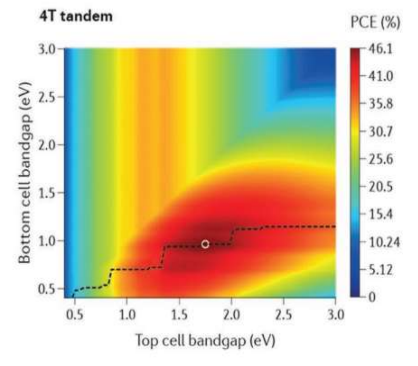

Fig 4: (a) Schematic of 2T perovskite/Si tandem, (b) J-V curve (c) EQE spectra for 2T perovskite/Si tandem solar cell. the total absorbance(1-R) is represented by dashed-grey line, the solid blue line represents EQE and the red line represents the transmittance. The total current density of the tandem is the sum of transmittance and the EQE. The light-grey shaded area represents the parasitic absorption loss and the associated current density losses are indicated [37,9]. (d) IZO as recombination layer with the area of $1.43 \mathrm{~cm}^{2}$ (e) theoretical maximum power conversion efficiency for $2 \mathrm{~T}$ and $4 \mathrm{~T}$ tandem [55].

The combination of perovskite and silicon solar cells in tandem configurations is of great interest due to the possibility of boosting efficiencies above $30 \%$ while reducing the cost per kilowatt. 
The first four-terminal perovskite/Si tandem solar cell was reported in 2014 with a power conversion efficiency of $17.9 \%$ [33]. In a double-junction solar cell Efficiency becomes $24 \%$ by including an interdigitated back contact (IBC) silicon cell, for the mechanically stacked steadystate efficiency is found $24.5 \%$ with the best alignment of top and bottom cell having bandgap $1.7 \mathrm{eV}$ fot top and $1.1 \mathrm{eV}$ for bottom cell. The most common used perovskite material is $\mathrm{MAPbI}_{3}$ (bandgap $=1.55 \mathrm{eV}$ ) [57], but this is not the optimum choice for perovskite-silicon multijunction solar cell. On compare with opaque with the cell efficiency $17.4 \%$, the semi-transparent perovskite cell shows a steady state efficiency $16.0 \%$ and for the wavelength of $720-1100 \mathrm{~nm}$, the transparency is found $84 \%$. The IBC solar cell retained $10.4 \%$ efficiency with semitransparent perovskite cell and $23.9 \%$ efficiency with single -cell [35]. So, $26.4 \%$ efficiency is the total efficiency for the mechanically stacked multijunction, whereas for 4T mechanically stacked perovskite/Si tandem solar cell the maximum efficiency is so far [35]. As shown in above figure 4(e), this optical simulation shows the most efficient bandgap alignment of both top $(1.7 \mathrm{eV})$ and bottom cell $(1.1 \mathrm{eV})$ in double-junction solar cell [56]. As we just discussed above that the commonly used perovskite material $\left(\mathrm{MAPbI}_{3}\right.$ ) has bandgap $1.55 \mathrm{eV}$ [57] and not a good choice for perovskite/Si tandem solar cell. To get a higher bandgap perovskite by replacing the iodide to bromide $(\mathrm{Br})$ in $\mathrm{MAPbI}_{3}$. However, by mixing these halides, the cell performance is decrease due to phase segregation under the illumination. The top cell is directly integrated with the bottom cell in $2 \mathrm{~T}$ monolithically tandem device. Lesser number of transparent electrode required is also an advantage for $4 \mathrm{~T}$. Transparent electrodes have the advantage that they reduce the manufacturing cost and also reduces the parasitic loss. However, the major concern is the tunnel junction between the two sub cell [58].

4T multijunction device required three transparent electrodes rather than this $2 \mathrm{~T}$ require only one transparent electrode. The parasitic loss in the transparent electrode and the reducing cost of manufacturing are the advantages. The first perovskite a silicon monolithic multijunction solar cell was fabricated in 2015 with the efficiency of $13.7 \%$ and Voc is $1.56 \mathrm{~V}$. To fabricate doublejunction devices based on the best-performing silicon technology, i.e., the a-Si: $\mathrm{H} / \mathrm{c}-\mathrm{Si}$ silicon heterojunction (SHJ), the device needs to work at temperatures below $2000 \mathrm{C}$ to prevent undesirable mobility at the a-Si: $\mathrm{H}$ layer. Moreover, better-quality perovskite composition, FAyMA1-yPbIxBr3-x, and a Spiro-OMeTAD/MoO3/ITO front contact were used to prepare the top cell. The combination of those improvements pushes the perovskite/Si tandem solar cell performance to a stabilized PCE of $18.1 \%$ [36].

\section{B. 4 T perovskite/Si Tandem solar cell}

The four-terminal mechanically stacked tandem based on perovskite/Si is first reported in 2014, in this architecture a transparent silver nanowire is used as a back contact and for the top sub cell a standard $\mathrm{FTO} / \mathrm{TiO}_{2} /$ perovskite/spiroOMeTAD is used [47]. This architecture results the efficiency of $12.7 \%$ and the transmittance is $60-70 \%$ in the wavelength range of 800 to $1200 \mathrm{~nm}$. In the figure 5A Four-Terminal perovskite/silicon tandem solar cell is shown and in 5B the performance of multi-crystalline silicon solar cell with efficiency of $11.4 \%$ as a rear device and the improved performance with efficiency of $17 \%$ is shown. Another approach for the 4T perovskite solar cell is using a Transparent Conductive oxide (TCO) as back contact [46], and on ITCO transparent contact, a buffer layer of MoOx is deposited by doing this an efficiency of $13.4 \%$ is achieved. The performance is also optimized further and achieve efficiency to $20.1 \%$ [45]. Approach for improving the efficiency is continued, another approach which shows the 
efficiency of 22.8\% [44] used an IZO in place of ITO as back contact and also, they place perovskite based top cell on the top of amorphous-Si/crystalline-Si device. The efficiency of four-terminal tandem solar cell is increased up to $25.2 \%$ and $23 \%$ for the area $0.25 \mathrm{~cm}^{2}$ and $1 \mathrm{~cm}^{2}$ by using a textured SHJ as back sub cell [49]. Another idea for the improvement of performance is given by [43], they used a chemical reaction in between the MoOx and iodide that ward off the damage by ITO sputtering process. By this $18 \%$ efficiency achieved by mechanically stacked $\mathrm{MAPbI} / \mathrm{c}$-silicon tandem which is stable at high (1000C) temperature.
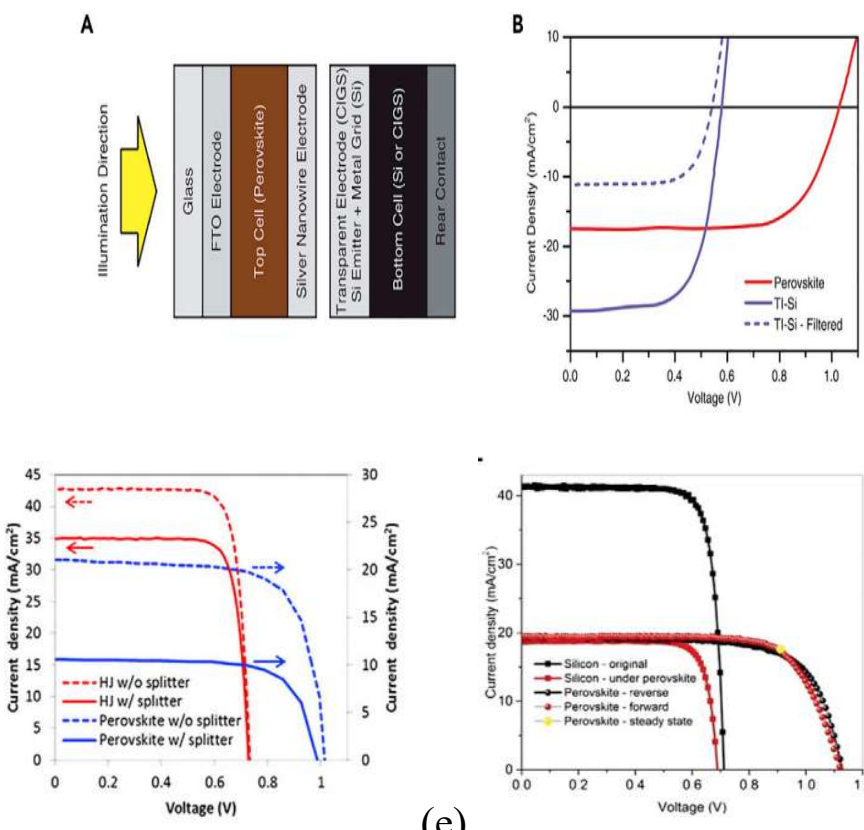

(D)

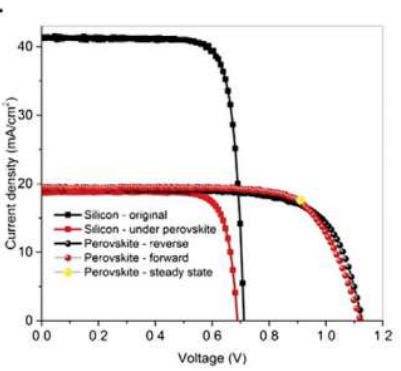

(e)

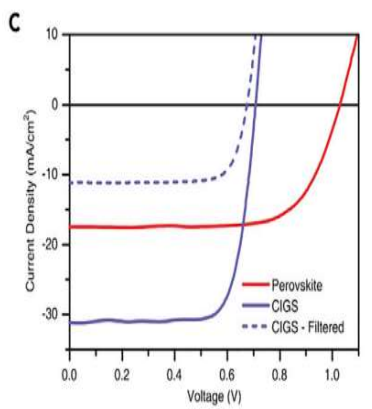

(f)

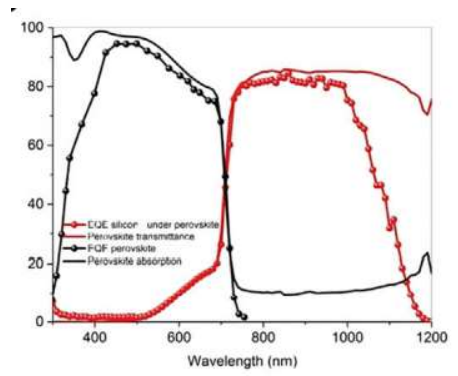

Figure 5: (A) Structure of Four-Terminal perovskite/silicon tandem solar cell (B) J-V curve (C) Silver nanowire are used as transparent rear contact in perovskite/CIGS [9]. (d) an optical splitting system. (e) record of mechanically stacked four-terminal perovskite/silicon tandem (f) EQE spectra.

$\mathrm{MAPbI}_{3}$ is consider as the optimum material as we discussed earlier but it has low bandgap of $1.6 \mathrm{eV}$ which is very less from the optimum bandgap $(1.75 \mathrm{eV})$ [90], when we consider $\mathrm{Si}$ devices an optimum bandgap is needed, so a perovskite material $\mathrm{FA}_{0.83} \mathrm{Cs}_{0.17} \mathrm{~Pb}\left(\mathrm{I}_{0.6} \mathrm{Br}_{0.4}\right)_{3}$ with bandgap $1.74 \mathrm{eV}$ is used as a filter for SHJ cell. This architecture proposed power conversion efficiency $22.4 \%$ [42]. This idea has been followed further [41], for enhance the formulation of perovskite. They add $\mathrm{Rb}$ in the above perovskite material composition $\mathrm{Rb}$ -

$\mathrm{FA}_{0.75} \mathrm{MA}_{0.15} \mathrm{Cs}_{0.1} \mathrm{PbI}_{2} \mathrm{Br}$ and obtain bandgap $(1.73 \mathrm{eV})$, by this the stability is improved and also used in the application in a double-junction configuration. Next approach is to use an interdigitated back contact (IBC) which leads the efficiency to $23.6 \%$ for four-terminal perovskite/Si and also negligible hysteresis as shown in figure 6(f) and 6(e). the optical coupling is good for the achievement of four-terminal tandem rather than mechanically stacked. In 2015 a dichroic mirror [34] is used for splitting the sunlight, they found that the photons having short wavelength are reflected and photons having long-wavelength are transmitted. They using a standard $\mathrm{FTO} / \mathrm{TiO}_{2} / \mathrm{MAPb}_{3} / \mathrm{Spiro} / \mathrm{Au}$ solar cell with an $\mathrm{SHJ}$ device [34]. Wavelength less than $550 \mathrm{~nm}$ are reflects to the perovskite device and the wavelength greater than $550 \mathrm{~nm}$ are 
transmitted towards the SHJ device by using an optical splitter, achieve an efficiency of $28 \%$. J$\mathrm{V}$ characteristics for this as shown in figure $6(\mathrm{~d})$. Moderate performance is observed on using the bandgap of $1.6 \mathrm{eV}$ but this attains poor voltage, so perovskite material $\mathrm{MAPbI}_{3}$ is replace with $\mathrm{MAPbBr}_{3}(\mathrm{Eg}=2.3 \mathrm{eV})$ [32]. Also in this paper [32] first time $\mathrm{MAPbBr}_{3}$ - and a $\mathrm{MAPbI}_{3}$ are optically coupled and reached the efficiency $13.4 \%$ in full perovskite tandem device. Dyesensitized tandem solar cell is used instead of silicon cell [31], by this so short-circuit current density is to $30.3 \mathrm{~mA} / \mathrm{cm}^{2}$ also it is capable of gather the photons around $1100 \mathrm{~nm}$ which is similar to silicon. PCE for DSSC is $10.2 \%$ with Voc 0.556 . With the use of DSSC optically coupled four-terminal tandem performance is $21.5 \%$ whereas we discuss that SHJ optically coupled four-terminal obtain $28 \%$ [34].

For the improvement of performance of solar cell recombination of charge carriers should be reduced. Recently in [59] this paper they fabricate a perovskite film of very high quality polycrystalline $\mathrm{MAPbI}_{3}$. Surface passivation of n-trioctylphosphine oxide (TOPO) is used that helps to reduce the recombination $[59,60]$, it also improves the power conversion efficiency from 24.3 to $27.9 \%$ and increase the internal photoluminescence quantum efficiency over $90 \%$. After the surface passivation the fermi-level is splitting of $1.28 \mathrm{eV}$, if this surface passivation is properly passivated indicates the maximum voc of $1.28 \mathrm{~V}$. Moving forward by the deposition of hydrogenated $\mathrm{In}_{2} \mathrm{O}_{3}$ and transparent ITO the device shows the efficiency of $19.2 \%$, yield high current and negligible hysteresis of arear $1.22 \mathrm{~cm}^{2}$. Recently an experiment testament, the perovskite material is formulated $\left(\mathrm{Cs}_{0.17} \mathrm{FA}_{0.83} \mathrm{~Pb}\left(\mathrm{Br}_{0.17} \mathrm{I}_{0.83}\right)_{3}\right.$ which is more thermally and moisture stable [37], and also tolerate the deposition of $\mathrm{SnO}_{2}, \mathrm{ZTO}$, and ITO by ALD, pulsedchemical vapor deposition, and sputtering. This leads to the efficiency of $23.6 \%$ with zero parasitic absorption.

\section{C. $3 T$ perovskite/Si tandem solar cell}

In this we introduce another configuration of tandem solar cell, three-terminal (3T) monolithic tandem solar cell whose architecture is shown in figure 6(a). this monolithic 3T consist of top cell of methylammonium lead halide with the material bandgap of $1.6 \mathrm{eV}$ and bottom cell of crystalline Si heterojunction-with-intrinsic-thin-film (HIT). In 3T configuration there is an auxiliary electrode which collecting the current and also acts as recombination layer and material used for this electrode is ITO film. For $3 \mathrm{~T} \mathrm{J-V}$ and EQE curves are shown in figure 6(b) and 6(c), by these curves we easily observed he current mismatching in between the sub cell [75]. The top sub cell must have properties of high absorbing photon material such as film of methylammonium lead iodide $\left(\mathrm{MAPbI}_{3}\right)$. The top sub cell consisted of stacked layers of $\mathrm{NiO}(15$ $\mathrm{nm}) /$ perovskite $(450 \mathrm{~nm}) /[6,6]$-phenyl-C(61)-butyric acid methyl ester (PCBM; $20 \mathrm{~nm}) / \mathrm{ZnO}(20$ $\mathrm{nm}) / \mathrm{ITO}(300 \mathrm{~nm}) / \mathrm{Ag}(150 \mathrm{~nm}$, grid), shown in figure 6(a) left. An ITO layer plays the same role as similar to other multijunction solar cells as recombination layer where from each sub cell holes and electrons are coming. As shown in figure 6(a) architecture of three-terminal consists of front and back contact of top cell, an additional front for majority carrier and IBC contact for bottom cell. So as shown in figure 6(a) the external three contacts of the tandem cell are connected with two circuits. The three contacts are (1) the front-back circuit connects the front contact of top cell to the rear contact of p-contact (2) interdigitated back contact connects the rear contacts of $\mathrm{n}$ and $\mathrm{p}$-contact. So, in this 3T configuration there is no need of current matching, no intermediate contacts, also it is compatible with mechanically stack or monolithically growth $[29,30]$. 
(a)
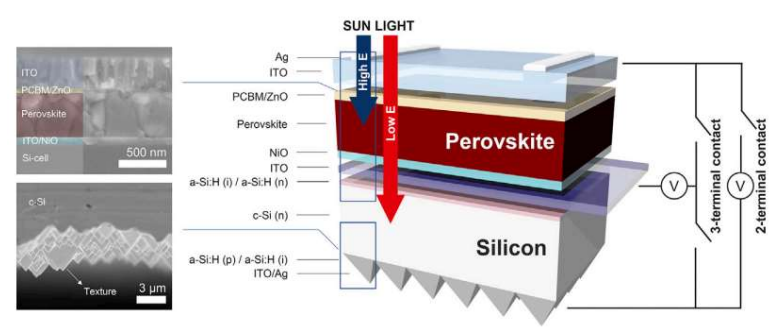

(c)

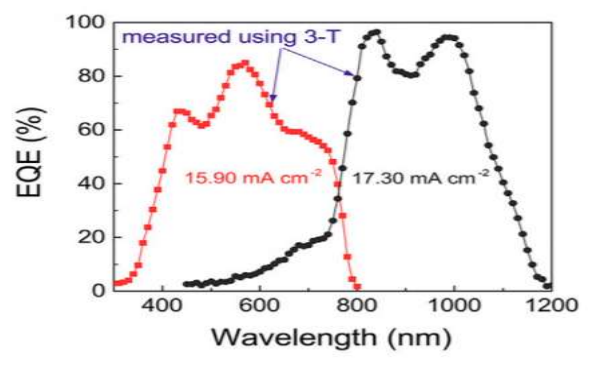

(b)

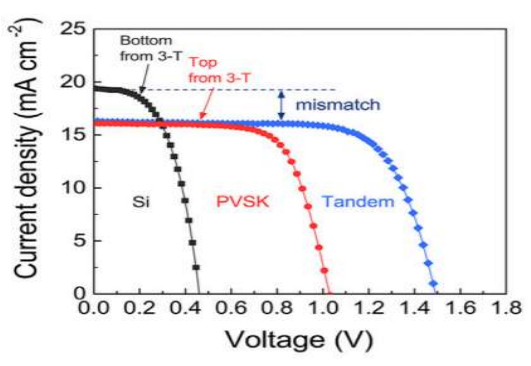

Figure 6: (a) Schematic of three-terminal perovskite/Si tandem solar cell (at the right side) and at the left side the FESEM image of perovskite top and bottom cell (b) J-V curve for each sub cell (c) EQE spectra of three-terminal tandem measured without any bias [40]

In above figure of 6(b) curves for each sub cell is presents for three-terminal tandem solar cell, by this $\mathrm{J}-\mathrm{V}$ curve we easily determine the current difference between each sub cell, also determine the current-limiting for each sub cell. EQE spectra as shown in figure 6(c), is the efficient way by which we can determine matching current density and also short-circuit current density. As shown in above figure 6(b) which represents the short-circuit current density of top cell is $16.10 \mathrm{~mA} \mathrm{~cm}{ }^{2}$ and for bottom cell $19.41 \mathrm{~mA} \mathrm{~cm}^{2}$, this indicate that the current-limiting of perovskite top cell and that short-circuit current density $\left(16.31 \mathrm{~mA} \mathrm{~cm}^{-2}\right)$ of tandem solar cell should be as same for top cell. this seems that Jsc of tandem solar cell is increased for the increase in Jsc of top cell. The total Voc of tandem is equal to the sum of Voc of sub cell, here the tandem Voc is $1.49 \mathrm{~V}$ and the Voc for top and bottom cell is 1.03 and $0.46 \mathrm{~V}$ (total Voc= $1.03+0.46)$. Next in figure 7 represents the optical properties of three-terminal monolithic tandem solar cell for different thickness of recombination layer. To minimize the reflection loss an anti-reflection film is deposited. In these figures 7 (A-C) of J-V curves with different thickness of recombination layer, the other parameters are reflected shown in the table 1.
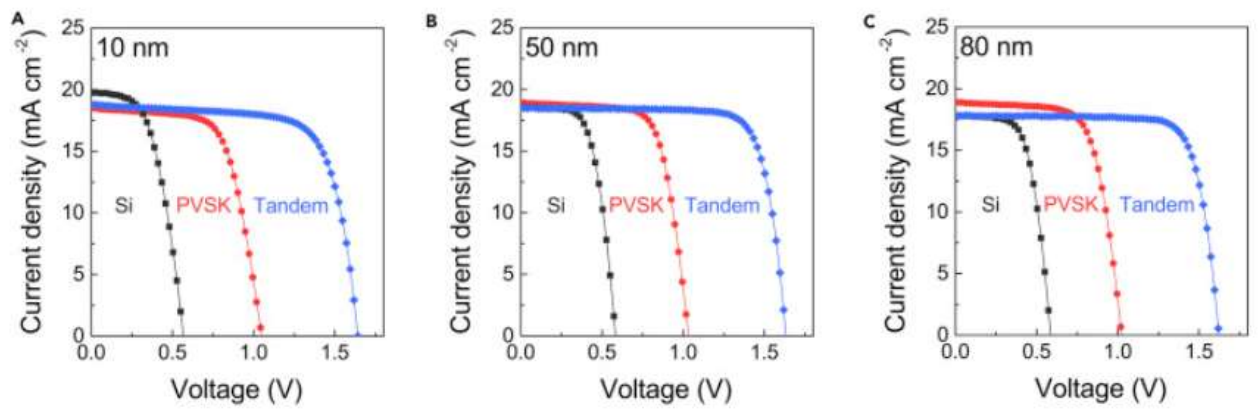

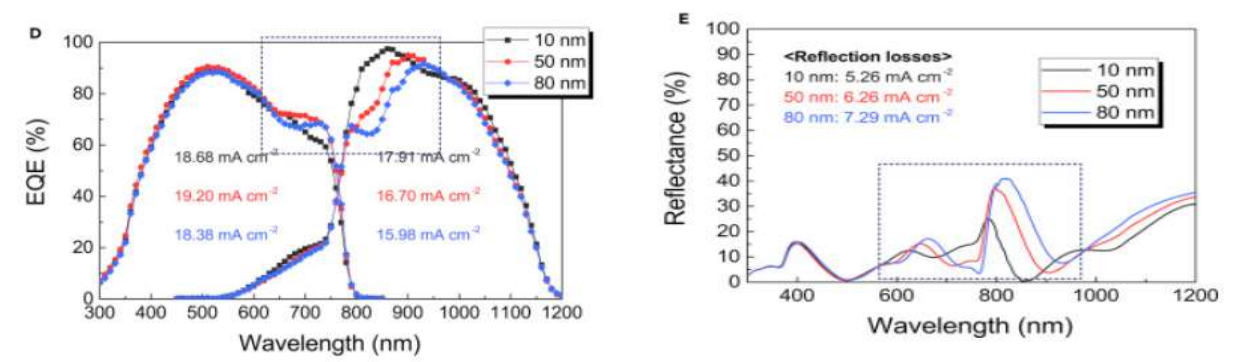

Figure 7: (A) with thickness of 10nm (B) with thickness of $50 \mathrm{~nm}$ (C) with thickness of 80nm of recombination layer (D) EQE spectra for these sub cell using three-terminal tandem (D) reflectance spectra of tandem solar cell without using of Ag electrode.

\begin{tabular}{|l|l|l|l|l|l|l|}
\hline & $\begin{array}{l}\text { Thickness } \\
(\mathbf{n m})\end{array}$ & $\begin{array}{l}\boldsymbol{J}_{\boldsymbol{s c}}(\boldsymbol{m} \boldsymbol{A} \\
\left.\mathbf{c m}^{-2}\right)\end{array}$ & $V_{\text {oc }}(\boldsymbol{V})$ & $\boldsymbol{F F}$ & PCE (\%) & $\begin{array}{l}\text { Corrected } \\
\text { PCE by } \\
\text { EQE (\%) }\end{array}$ \\
\hline $\mathrm{Si}$ & 10 & 19.78 & 0.57 & 0.54 & 6.04 & \\
\hline PVSK & & 18.46 & 1.05 & 0.68 & 13.26 & \\
\hline Tandem & & 18.74 & 1.66 & 0.72 & 22.54 & 21.41 \\
\hline Si & 50 & 18.56 & 0.59 & 0.63 & 6.82 & \\
\hline PVSK & & 18.91 & 1.04 & 0.72 & 14.18 & \\
\hline Tandem & & 18.48 & 1.65 & 0.78 & 23.78 & 21.49 \\
\hline Si & 80 & 17.82 & 0.59 & 0.63 & 6.63 & \\
\hline PVSK & & 18.89 & 1.03 & 0.72 & 14.02 & \\
\hline Tandem & & 17.80 & 1.63 & 0.79 & 22.91 & 20.58 \\
\hline
\end{tabular}

Table 1: Parameters summarized for different thickness of recombination layer shown in figure 7.

Parameter are affected by the thickness of recombination layer like current density, also change in reflectance. The current density is decrease with the increase in the thickness of ITO layer whereas thickness effect is more on bottom cell. The current matching affects the fill factor such as limits of current density of bottom and top cell are $80 \mathrm{~nm}$ and $10 \mathrm{~nm}$ device. For the $10 \mathrm{~nm}$ device the fill factor is lower by $\sim 10 \%$ as compare to other devices. While Voc doesn't have direct dependency on ITO thickness [74]. So, for the thickness of 10nm, 50nm, 80nm the overall device efficiencies are $22.54 \%, 23.78 \%$, and $22.91 \%$ measured from the $\mathrm{J}-\mathrm{V}$ curves a shown in above (Fig 7). It is clearly shown by the J-V curves that current density is perfectly matched for the thickness of 50nm recombination layer, in the curve of EQE spectrum shown in above figure 7(D) reveals the different results. When we observed the ITO thickness and EQE curve for the bottom cell, the current density is overestimated during the measurement of J-V curve. Observed the table 1 , there is decrease in the difference between the current densities of each sub cell on decreasing the thickness of ITO layer. Overall, the result is that the performance of tandem solar cell is affected by (1) ITO layer sheet resistance (2) thickness. Lesser the thickness layer of ITO lesser is the optical (reflection and absorption) losses. 
Up to now we discussed different configurations of perovskite/Silicon tandem solar cells, 2T, 3T, 4T. We discussed advantages and disadvantages of these configurations. We came to know that $3 \mathrm{~T}$ is almost optically similar to $2 \mathrm{~T}$ perovskite/Si tandem solar cell only an additional contact is present in 3T. also there is no current matching is required for both sub cell as need of $2 \mathrm{~T}$ perovskite/Si tandem. In $3 \mathrm{~T}$ the photocurrent density could be increased by the increase in the thickness of absorber layer [38]. We can easily observe the current mismatch in $3 \mathrm{~T}$ configuration by $\mathrm{J}-\mathrm{V}$ and EQE curves. In $2 \mathrm{~T}$ tandem the top perovskite behaves optically, absorbing absorbing most of the light before $800 \mathrm{~nm}$ and still exposing at longer wavelengths the parasitically absorptive behavior of the poly-SiOx layers [39]. For the 2T tandem you can easily measure the maximum power of the tandem solar cell by using $\mathrm{J}-\mathrm{V}$ curve whereas in $3 \mathrm{~T}$ tandem solar cells total maximum power is optimized when front cell and Si IBC are at their maximum power point. But in case of 4T the optimization of sub cell with the Si cell are independently because from the Si front contact lateral current extraction are not allowed by the sub cell. In mechanically stacked 4T device due to extraction of current through metal-gride there is no substantial power loss. Whereas, at the module level this is significant. Table 2 is shown below, observes that $3 \mathrm{~T}$ tandem efficiency exceeds $4 \mathrm{~T}$.

Table 2: Under the AM1.5G illumination comparing the performances of 2T, 3T, 4T for GaInP/Si tandem cell.

\begin{tabular}{llllc}
\hline Configuration & $\begin{array}{l}V_{\mathrm{FB}, \mathrm{mpp}} \\
(\mathrm{mV})\end{array}$ & $\begin{array}{l}V_{\mathrm{IBC}, \mathrm{mpp}} \\
(\mathrm{mV})\end{array}$ & $\begin{array}{l}J_{\mathrm{mpp}} \\
\left(\mathrm{mA} \mathrm{cm}^{-2}\right)\end{array}$ & $\begin{array}{l}\text { Eff. } \\
(\%)\end{array}$ \\
\hline 2T (GaInP + Si-FB) & 1940 & - & 15.8 & 30.6 \\
4T (GaInP) & 1310 & - & 15.8 & 20.6 \\
4T (Si-IBC) & - & 585 & 20.2 & 11.8 \\
4T (total) & - & - & - & 32.4 \\
3T (FB) & 1890 & - & 15.8 & 29.8 \\
3T (Si-IBC) & - & 594 & 4.49 & 2.66 \\
3T (total) & - & - & - & 32.5
\end{tabular}



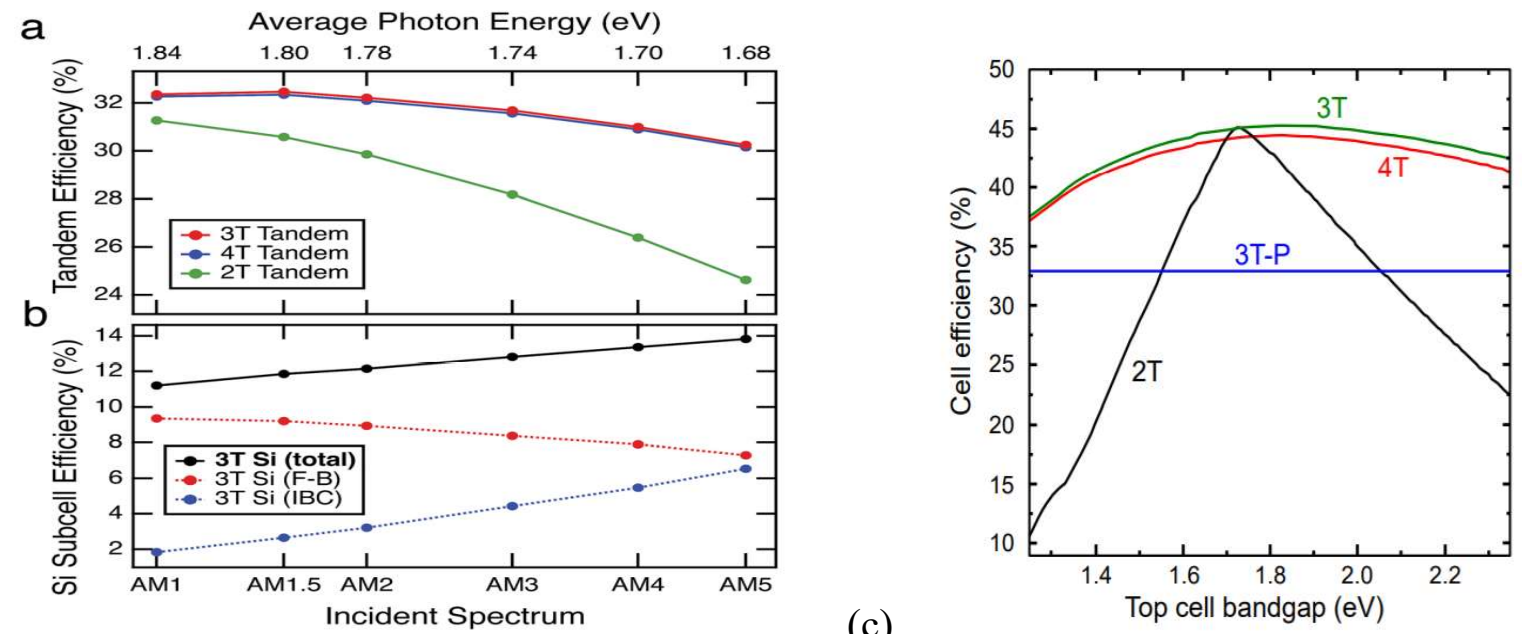

Figure 8: (a) For 2T, 3T, 4T tandem configuration, total tandem efficiency for GaInP/Si tandem (b) For 3T, under different spectra efficiency of each component (c) based on Si bottom cell, ideal solar cell efficiencies for 2T, 3T, 4T as a function of bandgap of top cell.

As we already discussed that in $3 \mathrm{~T}$ tandem an additional contact is present which offers an additional degree of freedom due to which the $3 \mathrm{~T}$ system is not fully covered by single $\mathrm{J}-\mathrm{V}$ curve. In the IBC mode the current is collected in between the back n-contact and the p-contact, whereas there is no current is collected at the top contact. As compared to 2T, 4T also have an advantage of no current matching. Under the same illumination 3T and 4T both have almost same performance, 3T tandems have ability to extract power from different connected circuits to 3T. In 3T if both top and bottom sub cell are not available, these high energy photons still can be collected by IBC circuit. 3T and 4T device have same spectral insensitivity whereas, 2T produces less energy as the energy of photon is reduced. Performance of $2 \mathrm{~T}$ tandem is also decrease as the requirement of current matching of sub cell whereas in 4T tandems cells are operated independently. 3T tandem configurations also have one more advantage that Voc is depends on the irradiance logarithmically, due to this voltage matching condition is more flexible as current matching condition. By this so we can say that 3T-IBC is a promising configuration. This 3T-IBC configuration has advantages of relieve of current matching condition and reduce the limitation of bandgap of top cell. Comparison of 2T, 3T, 4T is summarized in above figure 8, $\mathrm{Si}$ is used as bottom cell and comparison is based on connections of cell, bandgaps of top cell. However, 3T tandems avoiding the need for lateral conduction between the two cells and potentially a mechanism to improve the power conversion of monolithically grown tandem devices that are not currently matched and also maintains the fabrication advantages of $2 \mathrm{~T}$ tandem solar cell.

\section{CONCLUSION}

At the module level, we compare different configurations of perovskite/Si tandem solar cell. Now, we can say that tandem cells are highly efficient. In this work, we observe that the choice of the best tandem architecture depends on the characteristics of sub-cells and operating conditions. For $4 \mathrm{~T}$, the bottom cell current is about 3\% lower than that in $2 \mathrm{~T}$ and $3 \mathrm{~T}$ tandems due 
to parasitic absorption in additional ITO layers involved. When the perovskite top cell is not textured, the 4T configuration gives rise to additional reflection losses and correspondingly lower current-density in both top and bottom cells. For 2T, current matching for top and bottom cell are required. For 3T and 4T, having a thicker perovskite absorber will lead to higher photocurrent in the top cell but lower photocurrent in the bottom cell. In all above discussed configurations, we saw that potentially high current and output voltage will leads in higher efficiency for a larger thickness of perovskite. Whereas, thick perovskite layer has some issues in fabrication and also electrical losses. For current matched $2 \mathrm{~T}$ tandem, the current density is given with the corresponding perovskite thickness. according to our study, the highest energy is yield by the $3 \mathrm{~T}$ configuration and also have high current density due to large photogenerated in the absorber layer as compared to $4 \mathrm{~T}$ configuration, and higher robustness to spectral variations compared with $2 \mathrm{~T}$ architecture. For the perovskite top cell, the main challenge is to assure high Voc. For the improvement of perovskite itself with reduced interface recombination of the high bandgap perovskite top cell together with favorable energy alignment of the contact layers. this also improves fill factor. Given these results, we expect improvement in technology of photovoltaic would be possible.

\section{ABBREVIATIONS}

PCE: Power Conversion Efficiency

PV: Photovoltaic

PVSK: Perovskite

AC: Alternating Current

S-Q: Sohckley-Queisser

2T: Two-terminal

3T: Three-terminal

4T: Four-terminal

Voc: Open-circuit Voltage

Si: Silicon

CIGS: Copper Indium Gallium and Selenide

ETL: Electron Transport layer

HTL: Hole transport Layer
ICL: Interconnecting layer

TCO: Transparent Conductive Oxide

HOMO: Highest Occupied molecular orbital

LUMO: Lowest occupied molecular orbital

EQE: External Quantum Efficiency

Eg: Bandgap

FF: Fill factor

Jsc: Short-circuit current density

TCE: Transparent conductive electrode

IBC: Interdigitated Back contact

MAPbI3: Perovskite material

FB: Front-back

TCA: Transparent conductive Adhesive

TJ: Tunnel Junction

AM1.5: Air-mass 1.5

PECVD: Plasma-enhanced chemical vapor deposition

ALD: Atomic layer deposition 
ESL: Electron Selective layer

HSL: Hole selective layer

HIT: Heterojunction intrinsic thin layer
C-Si: Crystalline silicon

SHJ: Silicon Heterojunction

IZO: Indium zinc oxide

\section{AUTHOR CONTRIBUTIONS}

Shivani Chauhan and Rachna Singh contributed to the discussion and writing of the manuscript. CONFLICT OF INTEREST

The authors declare no conflict of interest.

\section{REFERENCES}

[1] Tyag, VV, Rahim Nurul, AA, Rahim, NA (2013) Progress in Solar PV technology: Research and achievement. Renewable and sustainable Reviews 20: 443-461

[2] J. Zhao et al., "20\% efficient silicon solar cell modules," Conference Record of the Twenty Third IEEE Photovoltaic Specialists Conference - 1993 (Cat. No.93CH3283-9), Louisville, KY, USA, 1993, pp. 1246-1249, doi: 10.1109/PVSC.1993.346943.

[3] A. Anantha, "Solar photovoltaic as an energy source for India," IECEC-97 Proceedings of the Thirty-Second Intersociety Energy Conversion Engineering Conference (Cat. No.97CH6203), Honolulu, HI, USA, 1997, pp. 2328-2333 vol.4, doi: 10.1109/IECEC.1997.658231.

[4] PNAS January 2, 2019116 (1) 7-10; https://doi.org/10.1073/pnas.1820406116

[5] Helmholtz-Zentrum Berlin für Materialien und Energie. "Perovskite/silicon tandem solar cells on the magic threshold of $30 \%$ efficiency: The current world record tandem solar cell provided stable performance for 300 hours - even without encapsulation." ScienceDaily. ScienceDaily, 10 December 2020

[6] Graetzel, M.; Janssen, R. A. J.; Mitzi, D. B.; Sargent, E. H. Materials Interface Engineering for Solution-Processed Photovoltaics. Nature 2012, 488, 304-312

[7] O'Regan, B. and Graetzel, M., "A low-cost, high-efficiency solar cell based on dye-sensitized colloidal TiO2 films”, $<\mathrm{i}>$ Nature $<$ i $>$, vol. 353, pp. 737-740, 1991. doi:10.1038/353737a0.

[8] All-Perovskite Tandem Solar Cells: A Roadmap to Uniting High Efficiency with High Stability Xiaopeng Zheng, Abdullah Y. Alsalloum, Yi Hou, Edward H. Sargent, and Osman M. Bakr Accounts of Materials Research 20201 (1), 63-76 DOI: 10.1021/accountsmr.0c00017

[9] Anaya, M., Lozano, G., Calvo, M.E., and Mi'guez, H. (2017). ABX3 perovskites for tandem solar cells. Joule 1, 769-793. 
[10] Noh, J.H., Im, S.H., Heo, J.H., Mandal, T.N., and Seok, S.I. (2013). Chemical management for colorful, efficient, and stable inorganicorganic hybrid nanostructured solar cells. Nano Lett. 13,1764 .

[11] Recent progress in developing efficient monolithic all-perovskite tandem solar cells Yurui Wang, Mei Zhang, Ke Xiao, Renxing Lin, Xin Luo, Qiaolei Han and Hairen Tan iopscience.iop.org/article/10.1088/1674-4926/41/5/051201

[12] T. Ibn-Mohammed, S.C.L. Koh, I.M. Reaney, A. Acquaye, G. Schileo, K.B. Mustapha, R. Greenough, Perovskite solar cells: An integrated hybrid lifecycle assessment and review in comparison with other photovoltaic technologies, Renewable and Sustainable Energy Reviews, Volume 80, 2017, Pages 1321-1344, ISSN 1364-0321, https://doi.org/10.1016/j.rser.2017.05.095.

[13] Understanding Degradation Mechanisms and Improving Stability of Perovskite Photovoltaics Caleb C. Boyd, Rongrong Cheacharoen, Tomas Leijtens, and Michael D. McGehee Chemical Reviews 2019119 (5), 3418-3451 DOI: 10.1021/acs.chemrev.8b00336

[14] S. Wagner and T. Otto, "Multilayer solar cell with thin polycrystalline silicon layers," Proceedings of 1994 IEEE 1st World Conference on Photovoltaic Energy Conversion - WCPEC (A Joint Conference of PVSC, PVSEC and PSEC), Waikoloa, HI, USA, 1994, pp. 1667-1670 vol.2, doi: 10.1109/WCPEC.1994.520539.

[15] Salama Abdelhady, Mohamed S. Abd-Elhady, Mennatallah M. Fouad, An Understanding of the Operation of Silicon Photovoltaic Panels, Energy Procedia, Volume 113, 2017, Pages 466475, ISSN 1876 6102, https://doi.org/10.1016/j.egypro.2017.04.041.

[16] François Gibelli, Myriam Paire, Laurent Lombez, Damien Aureau, Muriel Bouttemy, Arnaud Etcheberry, Yoshitaka Okada \& Jean-François Guillemoles (2018) Material challenges for solar cells in the twenty-first century: directions in emerging technologies, Science and Technology of Advanced Materials, 19:1, 336-369, DOI: 10.1080/14686996.2018.1433439

[17] Juan. C. Jimeno, Rubén Gutierrez, Vanesa Fano, Ahmed Habib, Carlos del Cañizo, Muhammad A. Rasool, Aloña Otaegi, A 3 Terminal Parallel Connected Silicon Tandem Solar Cell, Energy Procedia, Volume 92, 2016, Pages 644-651, ISSN 1876-6102, https://doi.org/10.1016/j.egypro.2016.07.031.

[18] Perovskite-Based Solar Cells: Materials, Methods, and Future Perspectives, 8148072, 2018, 1687-4110 UR - https://doi.org/10.1155/2018/8148072, DO - 10.1155/2018/8148072, JF Journal of Nanomaterials, PB - Hindawi

[19] M. Taguchi et al., "24.7\% Record Efficiency HIT Solar Cell on Thin Silicon Wafer," in IEEE Journal of Photovoltaics, vol. 4, no. 1, pp. 96-99, Jan. 2014, doi:

10.1109/JPHOTOV.2013.2282737. 
[20] A.K. Baranwal, T. Shiki, Y. Ogomi, S. S. Pandey, T. Ma, and S. Hayase, "Tandem dyesensitized solar cells with a back-contact bottom electrode without a transparent conductive layer,” RSC Advances, vol. 4, pp. 47735-47742, 2014.

[21] K. Xiao, R. Lin, H. Renxing, et al.., "All-perovskite tandem solar cells with $24.2 \%$ certified efficiency and area over $1 \mathrm{~cm} 2$ using surface-anchoring zwitterionic antioxidant," Nat. Energy, vol. 5, pp. 870-880, 2020.

[22] Conjugated Polymer-Based Organic Solar Cells Serap Günes, Helmut Neugebauer, and Niyazi Serdar Sariciftci Chemical Reviews 2007107 (4), 1324-1338 DOI: 10.1021/cr050149z

[23] M. A. Green, E. C. Cho, Y. Cho et al., "All-silicon tandem cells based on, "artificial” semiconductor synthesised using silicon quantum dots in a dielectric matrix," in Proceedings of the 20th European Photovoltaic Solar Energy Conference, p. 3, Barcelona, Spain, 2005

[24] A.Le Donne, A. Scaccabarozzi, S. Tombolato, S. Marchinonna, P. Harattini, B. Vodopivec, M. Acciarri, S. Binetti, "State of the Art and perspectives of Inorganic Photovoltaics", International Scholarly Research Notices, vol. 2013, Article ID 830731, 8 pages, 2013. https://doi.org/10.1155/830731

[25] Conjugated poly(thiophenes): synthesis, functionalization, and applications Jean Roncali Chemical Reviews 199292 (4), 711-738 DOI: 10.1021/cr00012a009

[26] Haohui Liu, Carlos D. Rodríguez-Gallegos, Zhe Liu, Tonio Buonassisi, Thomas Reindl, Ian Marius Peters, A Worldwide Theoretical Comparison of Outdoor Potential for Various SiliconBased Tandem Module Architecture, Cell Reports Physical Science, Volume 1, Issue 4, 2020 , 100037, ISSN 2666-3864, https://doi.org/10.1016/j.xcrp.2020.100037.

[27] Todorov, Teodor \& Gunawan, Oki \& Guha, S.. (2016). A Road towards 25\% Efficiency and Beyond: Perovskite Tandem Solar Cells. Mol. Syst. Des. Eng.. 1. 10.1039/C6ME00041J.

[28] Journal of Physics: Conference Series, Volume 398, 17th International School on Condensed Matter Physics (ISCMP): Open Problems in Condensed Matter Physics, Biomedical Physics and their Applications 2-7 September 2012, Varna, Bulgaria S Reynolds and V Smirnov 2012 J. Phys.: Conf. Ser. 398012006

[29] Schnabel, M. et al. "Three-terminal III-V/Si tandem solar cells enabled by a transparent conductive adhesive." Sustainable Energy and Fuels 4 (2020): 549-558.

[30] M. Schnabel et al., "Equivalent Performance in Three-Terminal and Four-Terminal Tandem Solar Cells," in IEEE Journal of Photovoltaics, vol. 8, no. 6, pp. 1584-1589, Nov. 2018, doi: 10.1109/JPHOTOV.2018.2865175.

[31] Kinoshita, T., Nonomura, K., Jeon, J.N., Giordano, F., Abate, A., Uchida, S., Kubo, T., Seok, S.I., Nazeeruddin, M.K., Hagfeldt, A., et al. (2015). Spectral splitting photovoltaics using perovskite and wideband dyesensitized solar cells. Nat. Commun. 6, 8834. 
[32] Sheng, R., Ho-Baillie, A.W.Y., Huang, S., Keevers, M., Hao, X., Jiang, L., Cheng, Y.-B., and Green, M.A. (2015). Four-terminal tandem solar cells using $\mathrm{CH} 3 \mathrm{NH} 3 \mathrm{PbBr} 3$ by spectrum splitting. J. Phys. Chem. Lett. 6, 3931-3934.

[33] C. D. Bailie, M. G. Christoforo, J. P. Mailoa, A. R. Bowring, E. L. Unger, W. H. Nguyen, J. Burschka, N. Pellet, J. Z. Lee, M. Gratzel, R. Noufi, T. Buonassisi, A. Salleo, M. D. McGehee, Energy Environ. Sci. 2015, 8, 956.

[34] Uzu, H., Ichikawa, M., Hino, M., Nakano, K., Meguro, T., Herna'ndez, J.L., Kim, H.S., Park, N.G., and Yamamoto, K. (2015). High efficiency solar cells combining a perovskite and a silicon heterojunction solar cells via an optical splitting system. Appl. Phys. Lett. 106, 3-7.

[35] T. Duong, Y. L. Wu, H. Shen, J. Peng, X. Fu, D. Jacobs, E. C. Wang, T. C. Kho, K. C. Fong, M. Stocks, Adv. Energy Mater. 2017, 7, 1700228.

[36] Mailoa, J.P., Bailie, C.D., Johlin, E.C., Hoke, E.T., Akey, A.J., Nguyen, W.H., McGehee, M.D., and Buonassisi, T. (2015). A 2-terminal perovskite/silicon multijunction solar cell enabled by a silicon tunnel junction. Appl. Phys. Lett. 106, 121105.

[37] 4. Bush, K.A., Palmstrom, A.F., Yu, Z.J., Boccard, M., Cheacharoen, R., Mailoa, J.P., McMeekin, D.P., Hoye, R.L.Z., Bailie, C.D., Leijtens, T., et al. (2017). 23.6\%-Efficient monolithic perovskite/silicon tandem solar cells with improved stability. Nat. Energy 2, 17009.

[38] F. Sahli, J. Werner, B. A. Kamino, et al.., "Fully textured monolithic perovskite/silicon tandem solar cells with $25.2 \%$ power conversion efficiency," Nat. Mater., vol. 17, pp. 820-826, 2018, https://doi.org/10.1038/s41563-018-0115-4.

[39] inngh, Manvika, Santbergen, Rudi, Syifai, Indra, Weeber, Arthur, Zeman, Miro and Isabella, Olindo. "Comparing optical performance of a wide range of perovskite/silicon tandem architectures under real-world conditions” Nanophotonics, vol. no. , 2021.

https://doi.org/10.1515/nanoph-2020-0643

[40] Ik Jae Park, Jae Hyun Park, Su Geun Ji, Min-Ah Park, Ju Hee Jang, Jin Young Kim, A Three-Terminal Monolithic Perovskite/Si Tandem Solar Cell Characterization Platform, Joule, Volume 3, Issue 3, 2019, Pages 807-818, ISSN 2542-4351, https://doi.org/10.1016/j.joule.2018.11.017.

[41] Duong, T., Wu, Y., Shen, H., Peng, J., Fu, X., Jacobs, D., Wang, E.C., Kho, T.C., Fong, K.C., Stocks, M., et al. (2017). Rubidium multication perovskite with optimized bandgap for perovskite-silicon tandem with over 26\% efficiency. Adv. Energy Mater. 7, 1700228.

[42] Mc Meekin, D.P., Sadoughi, G., Rehman, W., Eperon, G.E., Saliba, M., Horantner, M.T., Haghighirad, A., Sakai, N., Korte, L., et al. (2016). A mixed-cation lead mixed-halide perovskite absorber for tandem solar cells. Science 351, 151-155.

[43] Bush, K.A., Bailie, C.D., Chen, Y., Bowring, A.R., Wang, W., Ma, W., Leijtens, T., Moghadam, F., and McGehee, M.D. (2016). Thermal and environmental stability of 
semitransparent perovskite solar cells for tandems enabled by a solution-processed nanoparticle buffer layer and sputtered ITO Electrode. Adv. Mater. 28, 3937-3943.

[44] Werner, J., Dubuis, G., Walter, A., Lo“ per, P., Moon, S.J., Nicolay, S., Morales-Masis, M., De Wolf, S., Niesen, B., and Ballif, C. (2015). Sputtered rear electrode with broadband transparency for perovskite solar cells. Sol. Energy Mater. Sol. Cells 141, 407-413

[45] Duong, T., Lal, N., Grant, D., Jacobs, D., Zheng, P., Rahman, S., Shen, H., Stocks, M., Blakers, A., Weber, K., et al. (2016). Semitransparent perovskite solar cell with sputtered front and rear electrodes for a fourterminal tandem. IEEE J. Photovoltaics 6, 679-687.

[46] Lo“ per, P., Moon, S.-J., Martı'n de Nicolas, S., Niesen, B., Ledinsky, M., Nicolay, S., Bailat, J., Yum, J.-H., De Wolf, S., and Ballif, C. (2015). Organic-inorganic halide perovskite/ crystalline silicon four-terminal tandem solar cells. Phys. Chem. Chem. Phys. 17, 1619-1629.

[47] Bailie, C.D., Christoforo, M.G., Mailoa, J.P., Bowring, A.R., Unger, E.L., Nguyen, W.H., Burschka, J., Pellet, N., Lee, J.Z., Gra“tzel, M., et al. (2015). Semi-transparent perovskite solar cells for tandems with silicon and CIGS. Energy Environ. Sci. 8, 956-963.

[48] Mc Meekin, D.P., Sadoughi, G., Rehman, W., Eperon, G.E., Saliba, M., Horantner, M.T., Haghighirad, A., Sakai, N., Korte, L., et al. (2016). A mixed-cation lead mixed-halide perovskite absorber for tandem solar cells. Science 351, 151-155.

[49] Werner, J., Barraud, L., Walter, A., Bra“uninger, M., Sahli, F., Sacchetto, D., Te'treault, N., Paviet-Salomon, B., Moon, S.-J., Allebe' , C., et al. (2016). Efficient near-infraredtransparent perovskite solar cells enabling direct comparison of 4-terminal and monolithic perovskite/silicon tandem cells. ACS Energy Lett. 1, 474-480.

[50] Albrecht, S., Saliba, M., Correa-Baena, J.-P., Ja“ger, K., Korte, L., Hagfeldt, A., Gra“tzel, M., and Rech, B. (2016). Towards optical optimization of planar monolithic perovskite/siliconheterojunction tandem solar cells. J. Opt. 18, 64012.

[51] P. Tockhorn, P. Wagner, L. Kegelmann, J.-C. Stang, M. Mews, S. Albrecht, L. Korte, Three-Terminal Perovskite/Silicon Tandem Solar Cells with Top and Interdigitated Rear Contacts, ACS Appl. Energy Mater. 3 (2020) 1381-1392.

https://doi.org/10.1021/acsaem.9b01800.

[52] Tiazkis, R., Paek, S., Daskeviciene, M. et al. Methoxydiphenylamine-substituted fluorene derivatives as hole transporting materials: role of molecular interaction on device photovoltaic performance. Sci Rep 7, 150 (2017). https://doi.org/10.1038/s41598-017-00271-z

[53] P. Faine, Sarah R. Kurtz, C. Riordan, J.M. Olson, The influence of spectral solar irradiance variations on the performance of selected single-junction and multijunction solar cells, Solar Cells, Volume 31, Issue 3, 1991, Pages 259-278, ISSN 0379-6787, https://doi.org/10.1016/03796787(91)90027-M. 
[54] Shi, D., Zeng, Y., and Shen, W. (2015). Perovskite/c-Si tandem solar cell with inverted nanopyramids: realizing high efficiency by controllable light trapping. Sci. Rep. 5, 16504.

[55] Wang, Z., Song, Z., Yan, Y., Liu, S. (F.), Yang, D., Adv. Sci. 2019, 6, 1801704. https://doi.org/10.1002/advs.201801704

[56] Peng, J., Duong, T., Zhou, X., Shen, H., Wu, Y., Mulmudi, H. K., Wan, Y., Zhong, D., Li, J., Tsuzuki, T., Weber, K. J., Catchpole, K. R., White, T. P., Adv. Energy Mater. 2017, 7, 1601768 .

[57] Lee MM, Teuscher J, Miyasaka T, Murakami TN, Snaith HJ. Efficient hybrid solar cells based on meso-superstructured organometal halide perovskites. Science. 2012 Nov 2;338(6107):643-7. doi: 10.1126/science.1228604. Epub 2012 Oct 4. PMID: 23042296.

[58] J. P. Mailoa, C. D. Bailie, E. C. Johlin, E. T. Hoke, A. J. Akey, W. H. Nguyen, M. D. McGehee, T. Buonassisi, Appl. Phys. Lett. 2015, 106, 121105.

[59] Braly, I.L., deQuilettes, D.W., Pazos-Outón, L.M. et al. Hybrid perovskite films approaching the radiative limit with over $90 \%$ photoluminescence quantum efficiency. Nature Photon 12, 355-361 (2018). https://doi.org/10.1038/s41566-018-0154-z

[60] Koth Amratisha, Jitprabhat Ponchai, Paphada Kaewurai, Pimsuda Pansa-ngat, Kusuma Pinsuwan, Pisist Kumnorkaew, Pipat Ruankham, and Pongsakorn Kanjanaboos, "Layer-by-layer spray coating of a stacked perovskite absorber for perovskite solar cells with better performance and stability under a humid environment," Opt. Mater. Express 10, 1497-1508 (2020)

[61] Filipic, M., Lo“ per, P., Niesen, B., De Wolf, S.J.K., and Ballif, C. (2015). CH3NH3PbI3 perovskite/silicon tandem solar cells: characterization based optical simulations. Opt. Express $23,263-278$.

[62] Werner, J., Weng, C.H., Walter, A., Fesquet, L., Seif, J.P., De Wolf, S., Niesen, B., and Ballif, C. (2016). Efficient monolithic perovskite/ silicon tandem solar cell with cell area $>1 \mathrm{~cm} 2$ . J. Phys. Chem. Lett. 7, 161-166.

[63] Albrecht, S., Saliba, M., Correa-Baena, J.P., Lang, F., Kegelmann, L., Mews, M., Steier, L., Abate, A., Rappich, J., Korte, L., et al. (2016). Monolithic perovskite/silicon-heterojunction tandem solar cells processed at low temperature. Energy Environ. Sci. 9, 81-88.

[64] Werner, J., Niesen, B., Ballif, C., Adv. Mater. Interfaces 2018, 5, 1700731. https://doi.org/10.1002/admi.201700731

[65] Duong, T., Wu, Y., Shen, H., Peng, J., Fu, X., Jacobs, D., Wang, E-C., Kho, T. C., Fong, K. C., Stocks, M., Franklin, E., Blakers, A., Zin, N., McIntosh, K. R., Li, W., Cheng, Y-B., White, T. P., Weber, K., \& Catchpole, K. (2017). Rubidium Multication Perovskite with Optimized Bandgap for Perovskite-Silicon Tandem with over 26\% Efficiency. Advanced Energy Materials, 7(14), [1700228]. https://doi.org/10.1002/aenm.201700228 
[66] J. P. Mailoa, C. D. Bailie, E. C. Johlin, E. T. Hoke, A. J. Akey, W. H. Nguyen, M. D. McGehee, T. Buonassisi, Appl. Phys. Lett. 2015, 106, 121105.

[67] F. Sahli, B. A. Kamino, J. Werner, M. Bräuninger, B. Paviet-Salomon, L. Barraud, R. Monnard, J. P. Seif, A. Tomasi, Q. Jeangros, A. Jeangros, S. De Wolf, M. Despeisse, S. Nicolay, B. Niesen, C. Ballif, Adv. Energy Mater. 2018, 8, 1701609.

[68] L. Mazzarella, Y.-H. Lin, S. Kirner, A. B. Morales-Vilches, L. Korte, S. Albrecht, E. Crossland, B. Stannowski, C. Case, H. J. Snaith, R. Schlatmann, Adv. Energy Mater. 2019, 9, 1803241.

[69] E. Köhnen, M. Jošt, A. B. Morales-Vilches, P. Tockhorn, A. Al-Ashouri, B. Macco, L. Kegelmann, L. Korte, B. Rech, R. Schlatmann, B. Stannowski, S. Albrecht, Sustainable Energy Fuels 2019, 3, 1995.

[70] J. Zheng, H. Mehrvarz, F.-J. Ma, C. F. J. Lau, M. A. Green, S. Huang, A. W. Y. Ho-Baillie, ACS Energy Lett. 2018, 3, 2299.

[71] Shockley-Queisser Detailed Balance Efficiency Limit for Nanowire Solar Cells Nicklas Anttu ACS Photonics 20152 (3), 446-453 DOI: 10.1021/ph5004835

[72] Liu N, Wang L, Xu F, Wu J, Song T, Chen Q. Recent Progress in Developing Monolithic Perovskite/Si Tandem Solar Cells. Front Chem. 2020;8:603375. Published 2020 Dec 22.

doi:10.3389/fchem.2020.603375

[73] K.A. Bush, A. F. Palmstrom, Z. J. Yu, M. Boccard, R. Cheacharoen, J. P. Mailoa, D. P. McMeekin, R. L. Z. Hoye, C. D. Bailie, T. Leijtens, I.M. Peters, M. C. Minichetti, N. Rolston, R. Prasanna, S. Sofia, D. Harwood, W. Ma, F. Moghadam, H.J. Snaith, T. Buonassisi, Z. C.

Holman, S. F. Bent, M. D. McGehee, Nat. Energy 2017, 2, 17009

[74] Alexander J. Bett, Kristina M. Winkler, Martin Bivour, Ludmila Cojocaru, Özde Ş. Kabakli, Patricia S. C. Schulze, Gerald Siefer, Leonard Tutsch, Martin Hermle, Stefan W. Glunz, and Jan Christoph Goldschmidt ACS Applied Materials \& Interfaces 201911 (49), 45796-45804 DOI: 10.1021/acsami.9b17241

[75] Ik Jae Park, Jae Hyun Park, Su Geun Ji, Min-Ah Park, Ju Hee Jang, Jin Young Kim, A Three-Terminal Monolithic Perovskite/Si Tandem Solar Cell Characterization Platform, Joule, Volume 3, Issue 3, 2019, Pages 807-818, ISSN 2542-4351, https://doi.org/10.1016/j.joule.2018.11.017 